\title{
WHAT IS THEORY? WHAT IS ARCHAEOLOGY?
} Reply to Comments

\author{
Gavin Lucas \\ University of Iceland \\ Department of Archaeology \\ Sæmundargata 2, 101 Reykjavík, Iceland \\ gavin@hi.is
}

I perhaps should have called my paper the slipperiness of theory, if the comments on it are anything to go by. Indeed, both Johnson and Pétursdóttir explicitly ask me to define theory - but more on this in a moment. I should say this paper (and the keynote speech it was based upon) was largely written as a response to the theme of the 20I 4 Nordic TAG, entitled "Archaeology as a Source of Theory". I interpreted this in a very particular way by trying to link this idea with the current trend to promote a bottom-up or practice-led archaeology. I am happy to see from the comments that I am not alone at least in perceiving this trend. In pursuing this line of thought, my paper was driven very much by an internal dialogue, which is perhaps why Johnson also considered my paper too balanced and hard to disagree with. I was trying to think through the implications of what the call for a bottom-up approach really involves. At the same time, this equivocation or enumeration of the pros and cons of each side of an argument which runs throughout much of my text also may have led to a lack of clarity, leading others to find a lot to disagree with. Cornell, for example, raises a number of issues which I find sometimes difficult to connect to the intent of my paper, even though the issues he addresses are still of importance. 
It is perhaps appropriate then that I use this final response as an opportunity to continue the reasoning in my paper in a different direction by framing my response in terms of the question Johnson and Pétursdóttir ask of me: what is theory? This will involve some clarification of points in my paper, but mostly provide the missing dimension to understanding where I am coming from. It might seem unfair to devote my response to dealing with just one question from two commentators, but in doing so, I will of course engage with issues raised by the others; I use it merely as a position from which to address a wider set of concerns. Indeed I would like to thank all my commentators for offering up such insightful and considered thoughts on my paper. In responding, I will also change the register of my discussion from one of an auto-dialogic account to a more positional statement. Indeed, I sensed a recurrent dissatisfaction in several of the comments (most explicitly in Johnson, but also evident in Johannsen and Pétursdóttir) in the way I seemed to sit on the fence, and not take a more definitive position. Of course it is probably foolish to answer such a big question (what is theory?), especially in the short space of a reply to comments; however, I will as far as possible attempt to connect it to the themes raised in my original paper and the comments that followed.

Theory is everywhere; this seems to be one of the most basic points of commonality to all of us and an issue explicitly mentioned by Brück and Cornell. An archaeologist cannot not be theoretical, whatever he or she might think. But what does this really mean? Every year that I teach my archaeological theory course, the question "what is theory" raises its head right at the start. Let me begin then by offering here the same answer I give my students. There is theory and there are theories. Let us call them Theory I and Theory 2. No hierarchy is implied here, but I think it is important to distinguish the two, even if the line gets very grey sometimes. Theory I I take to mean something of a broad set of assumptions or prejudices which affect the way we look at the world; it can range from very widely shared ideological and cultural systems of conceptualization to more specific scholarly or academic paradigms and discourses, including Moore's concept-metaphors as discussed in my original paper. Theory 2 , on the other hand, refers to explanations or interpretations of a set of phenomena; these too can vary from the highly particular to the general or universal - from say a particular narrative about a site to Darwinian evolution. This distinction may share some commonality with what Cornell was implying in his reference to fields of theory and fields of theoretical debate (although I would have liked to see him elaborate more on this).

Now in discussing theory as a kind of "system of representation" (Theory I), of course it is rather pointless to talk about top-down or 
bottom-up, imported or home-grown; Brück, Johnson and Pétursdóttir all emphasize that such theory is shared and one could say it is like the air we breathe - it is everywhere. Like Foucauldian power, it is dispersed, distributed throughout our practices, including of course, our practices of developing theories, i.e. Theory 2. At the same time, though, Theory 2 can, to some extent, still be defined by the divisions I discussed in my paper: a theory can pertain to a very specific set of data (let us call it "middle range") or a much wider group (let us call this "Grand or General Theory"). It is important here not to conflate general or grand theory (which is an example of theory 2) with a system of representation (i.e. theory I): they are not the same. It is also important not to treat general theory and middle range theories as oppositional or directional: this is more of a continuum or spectrum and equally importantly, it is a twoway street. We don't need to choose whether to start from the bottomup or the top-down; in fact we probably cannot choose since we always already find ourselves in traffic going in both directions, as Johannsen and Pétursdóttir imply in their comments and as I also concluded (perhaps somewhat unclearly) in my original paper.

In my original paper, though, the failure to distinguish between theory $\mathrm{I}$ and 2 probably created ambiguities and confusion - for myself as much as for my readers. In many ways, my main interest was in theory 2 and that is what I want to focus on in the rest of my response, because it is theory 2 that remains, I believe, under-theorized (if you will forgive the expression). It is under-theorized in two ways; the first in a lack of discussion on how to build theory and what it is that makes a good theory. The second in a lack of discussion on the kind of questions archaeology can ask and which drive such theory building. The best way to explain further what I mean here is to return to my theory course. Over the thirteen weeks, I introduce students to different theories - generally of the grander type 2 , but using often more particular applications of the same type 2 to illustrate them. There are classes on evolutionism and on structuralism, for example, with case studies as discussion reading. I don't imagine this is that different to many other theory courses taught in other institutions, and indeed I use Johnson's introduction (2009) as my basic text book. At the same time, I have a sense that I am only teaching half a theory course; what is missing are classes on how to construct such theory. I show them how theory (type I and 2) is implicated in a particular case study. I even try and give the students what I consider good examples of theory and we discuss strengths and weaknesses of the case studies in our discussion. But there is little explicit teaching on constructing a good interpretation or explanation. It is as if what constitutes a good interpretation is always 
pre-empted and trumped by the question of which theory is being used. Theory somehow forestalls any attempt to discuss what counts as good archaeology - theoretically speaking! The feeling of unease is made all the more striking by the fact that when I was teaching a basic methods course, this problem never arose. I could teach the theory and principles of stratigraphy and I could teach them how to dig stratigraphically and to construct and analyse stratigraphic sequences so they could do this for themselves.

I am certainly not the first to point out this asymmetry between the way theory and methods are taught; indeed, a typical rejoinder is that methods can be taught, but theory 2 (i.e. interpretation) is more of an art. Theory classes teach students the basic concepts, but how you operationalize those concepts is too hard to pin down - indeed, by its very nature, it cannot be codified or systematized in the same way stratigraphy can. I am not really satisfied with this response. There is literature out there about constructing interpretation, about how to build an argument and recently, even some books have been published by archaeologists which address this topic (e.g. Gibbon 20I4; Orser 2015). Now one could argue that prescriptive accounts like this are biased by a particular theoretical stance; of course they are - but so is a Harris Matrix. Theory I is everywhere. Now while there are a number of aspects involved in building theory and what it is that makes one theory better than another, one of the most important concerns the question or questions which lie behind that theory.

Johnson argues that ultimately, any definition of theory depends on what we see as the goals of archaeology; by his own framing of the issue, I have therefore put the cart before the horse by discussing what theory is without recourse to this other question. Possibly - but here Johnson is largely talking about theory 2: what theories we decide to use certainly depends on what we see as the goals of archaeology. We would not use a theory of Darwinian evolution if we did not consider the goal of archaeology to be the study of long-term change (not that such a goal necessarily demands a Darwinian approach). But arguably, theory I is what defines the possibility of archaeology at all - of whatever flavour. Archaeology is largely conceivable as a project because it is embedded in a certain rationality which developed in Europe several centuries ago as Brück reminds us. So what archaeology is - what its goals are is always sandwiched between theory I and theory 2. With that said, though, in what way are the goals of archaeology connected to theory 2 - at least in relation to the specific issues made in my original paper?

Well, the most obvious relation perhaps concerns the role of archaeology as a science of generalization and how one defines generaliza- 
tion. Certainly in the heyday of Binford and MRT, there was an explicit distinction made between nomothetic (generalizing) and ideographic (particularizing) science (aka science vs. history) and the discussions of middle range theories and grand or general theory usually were framed in these terms, with archaeology aspiring to be nomothetic. In contrast, the post-processual reaction often characterized itself as particularizing, eschewing grand narratives. Of course like so many oppositions which defined these theoretical positions, this one was over-drawn and exaggerated. The application of structuralism and binary oppositions was no less dependent on massive generalizations about human behaviour than cultural evolutionism. If there was any difference, it is that those using models of cultural evolution sought to build up generalizations from particular cross-cultural data whereas those using structuralist models of material culture patterning started from such generalizations to help interpret particular data patterning. But I should not overplay this point as it is in danger of returning us to an opposition of top-down vs. bottom-up approaches. The point is, generalization occurs all the time in what we do and sometimes it is an assumption, sometimes a goal; moreover, I do not think you can use this to define the goals of archaeology - which means I don't think it should determine the nature of your theories either.

If this is the case, then I cannot see how the goals of archaeology are connected to the kind of theory one chooses insofar as they relate to the issues discussed in my original paper. On the other hand, they are no doubt related in other ways and while to go there may take us too far from the topic at hand, I would still like to make some remarks on the subject. One of the first points is that in discussing the goals of archaeology, one is also necessarily discussing the relationship of archaeology to other disciplines; to what extent are our goals shared and to what extent are they unique to us? On the one hand, a theory (type 2) can pertain to a very specific discipline because it pertains to a specific set of data. However, this is not to say that such specificity can be mapped onto the opposition of data and theory, where our data is what is unique and our theory (or question) is what is shared, which could be one implication of pushing the notion that all theory is shared, i.e. inter-disciplinary. Historians and archaeologists can share both data and theory but as several commentators pointed out, it is the integration of theory and data which matters. I assume this is what Cornell means by coherence, but Johannsen articulates it closer to my own position when he suggests that archaeologists are sometimes answering questions using a theory developed on very different kinds of data so a "fit" is never going to be satisfactory. And on reflection, I think he is right to critique the notion 
that even some concept-metaphors carry stronger ontological commitments than we might realize, commitments which simply do not square with the ontological nature of archaeological data. Thus the distinction between imported and home-grown theory can matter; but again not in order to preserve disciplinary self-respect, but simply because of the ontological and epistemological differences generated through the different materials and practices relevant to any given discipline.

Contrary to what Cornell and Pétursdóttir seem to imply, though, I am not arguing for disciplinary isolation; rather I am asking us to consider the grounds upon which our discipline connects with others, and the grounds upon which it does not. I think it is important to acknowledge this duality. Indeed, I am concerned by Pétursdóttir's argument for what seems like an erasure of disciplinary domains - that the archaeological record belongs to the same domain as quantum physics or rightwing politics. Of course there are connections and overlaps; but if we suggest they belong to the same domain, we end up with porridge functionalism, as Johannsen says. If they belong to the same domain, how do we distinguish what an archaeologist does from what a quantum physicist does? This is just going from one extreme to another. The challenge is to understand the connections - and the lack thereof. To argue that archaeology has its own domain is not the same as arguing it is hermetically sealed within that domain or that archaeological theory should respect disciplinary boundaries. Acknowledging the duality of archaeological theory does not mean it is a binary, either/or choice; just like the distinction of bottom-up and top-down, the distinction between specifically archaeological theory and shared theory is a continuum, and one which we may not be able to, or even want to, define in advance. Rather it is something we are constantly working at. Thus even if theory I can be described as shared, theory 2 is much more closely tied up to our disciplinary identity and what we think archaeology is about, which is why I believe the distinction between theory I and theory 2 is relevant.

The critical question for me is: what is it that defines the archaeological domain? What are the questions that count - for archaeology? We could draw these questions purely from the abstract domain of theory I or even some of the grander versions of theory 2 , but that is to deny the power of the archaeological domain to generate questions of its own. It is also to fall potentially into a cul-de-sac of questions which the archaeological domain is simply unable to answer, as Johannsen reminds us. One of the fruitful aspirations of a bottom-up approach is to at least acknowledge this issue. But how do we start to characterize this in terms of the goals of archaeology; how do we define the domain of archaeology and its questions? This is where I share common 
ground with archaeologists like Pétursdóttir, for I believe an attentiveness to our objects, to our practices, should be our starting point. As I discussed in my paper, the "bottom-up" in current discourse is closely associated with an ontological turn which emphasizes the "bottom" in terms of the things we deal with as things rather than as data. It is their ontological status that is highlighted, not their epistemological one. At the same time, though, there are clear epistemological implications, as the bottom-up approach implies, and as Pétursdóttir argues in her comments. Here, I may have perhaps been too quick to step past this point in my original paper. For as Pétursdóttir suggests, the ontological turn has allowed us to critique the idea that our epistemological stance to the data should be one of translation. That the data are simply a proxy for something else - e.g. society, ideology etc., classically phrased as the "Indian behind the artefact". This is part of a critique of a hermeneutic or interpretive epistemology which sees objects as simply signs of something else (see especially Olsen 20I0). In contrast, she suggests the things themselves are enough - we do not need to go beyond them. Immediately, this would seem to challenge many of the conventional goals and questions of archaeology.

Now I share something of the spirit of this critique, but as it is stated, there is simply too much ambiguity around it. Consider something as ubiquitous as a potsherd. Now we can just treat this object as it is, but to disregard the fact that it was once part of a larger whole (i.e. the pot), would seem to me to remove one of the most important aspects of archaeology: time. To understand the potsherd as an object in time, we need to perform a process of translation, we need to get to something else that is not the potsherd, but that the potsherd points to - the whole pot. Even Chapman's fragmentation thesis, which reminds us the sherds can be meaningful as sherds, is still dependent on the whole pot relation (Chapman \& Gaydarska 2007).

Now it is possible Pétursdóttir would not include the example of the sherd-to-pot in her critique, only if the sherd is made into some epiphenomenon of something else, like cultural identity. But I am not so sure it is that clear when this epiphenomenalization occurs, nor if there is not some unacknowledged counter-denigration of certain kinds of things (e.g. ideas, beliefs) - despite the ostensible symmetry given to all things under the new materialism. For example, how does one justify drawing the line between the sherd being connected to a whole pot and the sherd being connected to an ideology of cultural identity? Ultimately, I wonder if this critique of a hermeneutic epistemology is not misdirected; the fact that, as archaeologists, we always strive to go beyond the potsherd is because of the absences the sherd elicits in its temporal register. It is 
about the fact that archaeology is a historical discipline. My concern is with the historical ontology of the potsherd, i.e. that it was once part of a pot, but this former state of existence no longer exists - is absent. It is not about making the sherd epiphenomenal. Nor, should I add, is it about defining the goal of archaeology as a reconstitution of totality based on the idea of the archaeological record as incomplete; this I have discussed elsewhere so I will not repeat it here (see Lucas 20I2, 20I5).

Now of course if Pétursdóttir is arguing that even the whole pot is going too far and rather wants to just stick to the sherd itself, then we definitely have a very different idea of the purpose of archaeology. That being the case, I will not push this point further. I will however end by pushing another point which causes perhaps the greatest disagreement among archaeologists, especially regarding their reception of the new materialism. It concerns how we define the archaeological domain in relation to humans. I have already stated one definition of this domain and its question concerning an enquiry into the historical or temporal ontology of things; but as it stands, this still covers a universe of possibilities. Astrophysics studies things in their temporal ontology. Any enquiry or questioning needs to make selections, to define fields of relevance; on what further basis (beyond the temporal) do we circumscribe the limits of our concern - as archaeologists? Even though we deal with things, for me, humans as one type of thing always circumscribe the limits of what other kinds of things we choose to devote our attention to as archaeologists. We don't study volcanoes in the same way a geologist would - even if there is some overlap. However fluid and permeable its boundaries are, there is still a recognizable domain of the archaeological and although many qualities circumscribe it, the human is critical. This notion of circumscription may also help us bypass the problem of anthropocentrism; it not about humans necessarily being the centre of attention, but about humans defining the parameters of that attention. We can study an axe without studying the human who made it or wields it; but the fact that we choose an axe to study at all (as opposed to a supernova) is because of the human involvement in that axe's existence. In this sense, I might rather prefer the designation of archaeology as a perianthropic or synanthropic science than an anthropocentric one.

Now I realize this somewhat brief and ugly definition of the goal of archaeology - as the study of the historical ontology of perianthropic things - is probably not going to appeal to very many people! But I would like to underline that this is simply a starting point; it by no means excludes questions of a broader ethical or political dimension, including the question of why this question is important. My aim here has been rather modest in its ambition; I wanted to see what it is that specifically 
defines the archaeological domain by starting from a position within that domain itself. This has a certain circularity to it, I realize - but I don't see it as a vicious one, but rather a strategic one. Johnson mentions the recent paper in American Antiquity which outlines 25 grand challenges for archaeology (Kintigh et al. 20I4); I am not going to take issue here with any of these challenges, rather I would just point out that they appear to have been devised from a very top-down perspective. Even though they engage specifically with how the archaeological record can answer these challenges, there is no sense that these questions have been generated by our engagement with the archaeological record itself. I don't want to overplay the difference between top-down and bottom-up; what I want to do is elevate the idea of the archaeological. What is the archaeological domain? We cannot offer any goals for archaeology without discussing this at the same time.

So where does all this take us? Perhaps the key point to emerge from this discussion is that theory has become too broad a term to be useful anymore. In my original paper I talked about theory as a practice, or rather as an element in any archaeological practice. In this response I distinguished between two broad kinds of theory. But frankly the term theory just seems inadequate. Theory 2 is better called something else like "interpretation" (and usually is), as "theory" seems too broad a term; theory I, on the other hand, is so pervasive and distributed that the word "theory" seems conversely too narrow and specific. In a way, the term theory may only get in the way of engaging with the important topics of formulating questions that count and defining methods that work. What we have been calling theory for the past half a century pervades both of these topics, but all of this only matters insofar as we triangulate it with our understandings of what the archaeological domain is.

\section{REFERENCES}

\section{Literature}

Chapman, J. \& Gaydarska, B. 2007. Parts and Wholes: Fragmentation in Prehistoric Context, Oxford: Oxbow Books.

Gibbon, G. 20I4. Critically Reading the Theories and Methods of Archaeology: An Introductory Guide. Lanham: AltaMira Press.

Johnson, M. 2009. Archaeological Theory: An Introduction (2nd edition). WilleyBlackwell.

Kintigh, K., Altschul, J. H., Beaudry, M. C., Drennan, R. D., Kinzig, A. P., Kohler, T. A., Limp, F. W., Maschner, H. D. G., Michener, W. K., Pauketat, T. R., Peregrine, P., Sabloff, J. A., Wilkinson, T. J., Wright, H. T. \& Zeder, M. A. 20I 4. Grand challenges for archaeology. American Antiquity. Vol. 79:I. Pp. 5-24. 
Lucas, G. 20I 2. Understanding the Archaeological Record. Cambridge University Press.

Lucas, G. 20I4. "Evidence of What? On the Possibilities of Archaeology". In: Wylie, A. \& Chapman, B. (Eds). Material Culture as Evidence. Pp. 3II-323. London: Routledge.

Olsen, B. 20I0. In Defense of Things: Archaeology and the Ontology of Objects. Lanham, MD: AltaMira Press.

Orser, C. 2015. Archaeological Thinking: How to Make Sense of the Past. Lanham: Rowman \& Littlefield Publishers. 